\title{
ENTRE O VISÍVEL E O INVISÍVEL: A IMAGEM COMO MATERIALIZAÇÃO DA ENCANTARIA
}

\author{
Maria Fernanda Canova Vasconcelos* \\ Silvio Ruiz Paradiso**
}

RESUMO: O presente trabalho é fruto de uma pesquisa em poéticas visuais motivada pela busca por utilizar a arte como representação iconográfica da encantaria. Foram escolhidos como tema os caboclos e os encantados, seres míticos e invisíveis, presentes no Tambor de Mina, religião afro-brasileira fortemente encontrada no Maranhão e no Pará, que se apresentam em nosso mundo através do transe dos membros de tal crença. Para tanto, foi realizado um estudo na Casa de Mina de Yemanjá e Ogum, em Maringá-PR, com os próprios encantados, bem como com praticantes dos ritos de matriz africana. O foco se deu nas investigações acerca de suas identidades perante a religião, e também nas pesquisas sobre as possibilidades de se construir a imagem como um desdobramento material do espírito imaterial, tendo como ponte diálogos, vivências e percepções. Como resultado, têm-se retratos pintados com pastel oleoso sobre papel, representando figurativamente as entidades pesquisadas.

PALAVRAS-CHAVE: Poéticas visuais; Iconografia; Tambor de Mina; Encantaria brasileira.

\section{BET WEEN THE VISIBLE AND THE INVISIBLE: THE IMAGE AS THE MATERIALIZATION OF ENCHANTMENT}

\begin{abstract}
Current paper is the result of a research on visual poetics on the use of art as the iconographic representation of enchantment. The theme of the caboclos and the enchanted, mythic and invisible beings, in the African-Brazilian religious denomination Tambor de Minas, are iconic in the states of Maranhão and Pará, Brazil. The mythical beings are materialized in the world through the members' transe. The study was undertaken in the Casa de Mina de Yemanjá e Ogum, in Maringá, Brazil, with the enchanted people and the participants in the rites of the African religion.

\footnotetext{
* Especialista em Arte na Contemporaneidade pelo Centro Universitário Cesumar (UniCesumar), Maringá, Brasil.

** Doutor em Estudos Literários pela Universidade Estadual de Londrina (UEL). Docente da Universidade Federal do Recôncavo da Bahia (UFRB), Brasil. E-mail: silvinho@ufrb.edu.br
} 
Investigation focused on their identities within the denomination and in research work on the possibilities of building an image as the material development of the immaterial spirit, underscoring dialogues, experiences and perceptions. Results are materialized in pictures figuratively representing the spiritual entities under analysis, on oil paint on paper.

KEY WORDS: Visual poetics; Iconography; Tambor de Mina; Brazilian enchantment.

\section{INTRODUÇÃO}

Neste trabalho, foram investigadas as possibilidades de a produção artística visual (visível) servirem como meio de representação material do "anima”, espírito incorpóreo, mutável e fluido (invisível) dos seres míticos conhecidos como caboclos e encantados, que se manifestam por meio de transe ritualístico dos adeptos das religiões afro-brasileiras, em especial, o Tambor de Mina, na Casa de Mina de Yemanjá e Ogum, em Maringá-PR. Os meios utilizados para fazer a ponte entre estes seres estudados e as imagens a serem produzidas em sua semelhança envolveram relatos verbais e percepções pessoais, mediante diálogos e conversas informais com os próprios encantados e com os adeptos da religião, assim como observações realizadas durante ritos e festas abertos ao público.

A criação de imagens é um elemento importante da manutenção e memória da cultura material produzida pelas religiões, tendo as de matrizes africanas já um grande referencial imagético presente em seus ritos e altares, imagens essas de herança africana ou híbridas com a tradição católica (LOPES, 2015). No entanto, segundo Ferretti (1997), os terreiros de Mina partem de uma tradição em que somente os santos possuiriam imagens, herança do culto hagiográfico, enquanto que os caboclos e encantados seriam identificados apenas pelos fios de conta (guias) de suas famílias míticas (das Matas, Codó, Bandeira, Baia etc.), em vez de uma representação individual. Devido a isso, buscou-se criar uma iconografia relativa às entidades caboclas e encantadas na Mina, por meio de retratos falados. 


\section{ENCANTARIA NO TAMBOR DE MINA E SUA (NÃO) IMAGEM}

A Casa de Mina de Yemanjá e Ogum, no município de Maringá-PR, onde foram realizadas as vivências que embasaram a pesquisa, é descendente da Casa das Minas de Tóia Jarina, localizada no Estado de São Paulo, casa essa responsável por trazer o Tambor de Mina para o sudeste do país, e dali sua expansão para o sul (PRANDI; SOUZA, 2011).

Originária do Maranhão, no século XIX (LIMA; SAMPAIO, 2014), o Tambor de Mina teria sua raiz nos povos do antigo Daomé, em África, e atual Benim. No Brasil, sua gênese acontece através do culto Jeje, mesclando-se com o culto da Encantaria, tendo predominância em seus Estados de origem, isto é, Maranhão e Pará, ainda que as mencionadas expansões venham acontecendo. O nome, Tambor de Mina, segundo Prandi (2005, p. 65), deve-se a uma "[...] alusão à presença constante dos tambores nos rituais e aos escravos minas, como eram ali designados os negros sudaneses". Dialoga diretamente com a Umbanda e o Candomblé, podendo também abrigar entidades dessas linhas 3 . O Tambor de Mina ainda não é tão popular no sul do Brasil, onde a Casa estudada se encontra, mas conta com vários pesquisadores dedicados a estudá-la pelo país (PRANDI, 2005).

As entidades espirituais cultuadas no Tambor de Mina são os "[...] orixás e voduns jêje/nagô, 'nobres, gentis', entidades brasileiras como caboclos, índios e seres da mitologia indígena como mãe d'água, curupira e uma infinidade de outros" (SANCHES, 2002, p. 166 apud FONSÊCA, 2015, p. 47). Elas identificam-se ainda com linhagens e famílias, apresentando, desde os voduns até os caboclos, um pertencimento a grupos específicos com uma identidade social relacionada a funções ou regiões de origem (dentre os caboclos, há os Boiadeiros, os Marinheiros, os da família de Codó, os Baianos etc.).

Uma particularidade do Tambor de Mina é a presença da encantaria, sendo seu culto uma parte muito importante desta religião (PRANDI; SOUZA, 2011). Segundo Alcantara (2015, p. 18), o termo encantado refere-se a uma

\footnotetext{
${ }^{3}$ Sobre isso, Prandi e Souza (2011, p. 220), afirmam que “[...] as famílias dos encantados têm também absorvido caboclos da umbanda e do candomblé, justificando-se tal agregação por meio de parentescos míticos que são reelaborados a partir de lendas que fazem parte das tradiçóes da encantaria de mina e da umbanda".
} 
[...] categoria de seres espirituais, pessoas que viveram na terra e desapareceram misteriosamente, aparentemente vencendo a morte e que, acredita-se, passaram a viver em outro plano, passando, assim, a habitar as encantarias ou 'incantes', situados 'acima da terra e abaixo do céu', geralmente em lugares afastados dos humanos, ou que nunca tiveram corpo físico.

Prandi e Souza (2011, p. 217-218) reforçam essa ideia ao afirmarem que os adeptos da religião creem que "[...] os encantados são espíritos de pessoas que um dia viveram e que não morreram, mas se 'encantaram', passando a existir no mundo 'invisível', do qual retornam ao mundo dos homens no corpo de seus iniciados, em transe ritual". São, portanto, entidades que têm por característica a invisibilidade, assumindo uma imagem e uma identidade visível em nosso mundo físico e material ao se manifestarem por meio de transe mediúnico, e apresentam-se como seres que não conheceram a morte, não tendo passado pela experiência da perda da matéria, ou mesmo seres que nunca chegaram a ter matéria, o que os diferem dos caboclos ${ }^{4}$ da Umbanda.

Outro ponto de divergência entre os caboclos encantados com os caboclos da Umbanda diz respeito ao

[...] uso de imagens (estátuas) para representá-lo [o caboclo]. Nos terreiros de Mina mais antigos ou presos ao modelo da Casa das Minas e da Casa de Nagô, só os santos têm estátuas. As entidades espirituais são identificadas por guias (colares de contas) e estes, representam mais a sua família do que cada entidade individualmente. (FERRETTI, 1997, p. 8).

Assim, percebe-se que a questão da imagem em relação aos caboclos e encantados no Tambor de Mina é limitada: somente pessoas dotadas de uma percepção extrassensorial poderiam enxergá-los, enquanto ao público comum

\footnotetext{
${ }^{4}$ Segundo Shapanan (2011, p. 319) "A palavra caboclo, muito comum na encantaria, é um nome genérico usado na mina para quase todos os encantados [...].”. Como o foco do trabalho foram os caboclos encantados do tambor de mina, é importante ter em mente que esta nomenclatura é comum em outras religiões afro-brasileiras, ainda que os seres por ela denominados apresentem diferenças entre si.
} 
caberia apenas a identificação simbólica, por meio dos objetos rituais (como a guia) ou objetos de predileção da entidade ao se manifestar no transe através do adepto (como chapéus e adereços), o que se daria, especialmente para o não adepto, apenas durante a experiência dentro do terreiro.

\section{A ICONOGRAFIA RELIGIOSA E AS RELIGIÕES AFRO-BRASILEIRAS}

Antes de abordarmos o processo de construção das imagens dos caboclos encantados do Tambor de Mina, relevante se faz levantar as relações da iconografia com a religião, ou com a representação do espírito, por essência, invisível.

O termo iconografia parte do grego eikonographía, e significa "Arte de representar por imagens" (ICONOGRAFIA, 2019). As discussões sobre o que é "imagem" e suas relações com o "invisível", por sua vez, mobilizaram pesquisadores ao longo da história. Mitchell (1986) nos apresenta a complexidade do assunto ao nos recordar que as imagens não são apenas pictóricas, mas também mentais, verbais e perceptivas, sendo a própria ideia da imagem uma imagem em si, conceito já discutido em Aristóteles e Platão. Segundo o autor,

'Idea' comes from the Greek verb 'to see', and is frequently linked with the notion of the 'eidolon', the 'visible image' that is fundamental to ancient optics and theories of perception. [...] [The Platonic tradition] distinguishes the eidos from the eidolon by conceiving of the former as a 'suprasensible reality' of 'forms, types, or species', the latter as a sensible impression that provides a mere 'likeness' (eikon) or 'semblance' (phantasma) of the eidos. (MITCHELL, 1986, p. 5)5.

Ou seja, "ideia" e "imagem" possuem uma ligação etimológica na língua grega, e ainda que Platão tenha proposto uma ruptura entre os dois conceitos, em

\footnotetext{
5 “'Ideia' vem do verbo grego 'ver', e é frequentemente ligada à noção de 'eidolon', a 'imagem visível' que é fundamental à ótica antiga e às teorias da percepção. [...] [A tradição platônica] distingue o eidos do eidolon ao conceber o primeiro como uma 'realidade supersensível' de 'formas, tipos, ou espécies', o último como uma impressão sensível que provê uma mera 'semelhança' (eikon) ou 'aparência' (phantasma) do eidos" (tradução nossa).
} 
que a ideia (eidon) seria a realidade e a imagem apenas um ídolo (eidolon) dessa realidade, um ícone (eikon), semelhança e aparência, Mitchell (1986, p. 5) opta por tratar a ideia como imagem e observar e estudar ambas em suas capacidades de se constituírem como duplos, traduzindo-se, por exemplo, na forma como somos capazes de "[...] depict the act of picturing, imagine the activity of imagination, figure the practice of figuration" .

Baitello Júnior (2005 apud ANDRIOLO, 2018, p. 24) corrobora com esse ponto de vista ao descrever " [...] a imagem como a criação de uma segunda realidade em um jogo entre presença e ausência. Toda imagem tem dupla face, uma é visível aos olhos, outra é invisível [...]", remetendo ao sentido de imagem-presença, o que Pelegrinelli (2014, p. 143), tomando por referência Russo (2011), afirma ser

[...] a imagem que evoca um significado de presentificação para além do significado contido em sua pura visualidade. A ideia comum de representação é a de expor verbal, escrita ou visualmente algo que faz parte de nosso universo mental. [...] A imagem religiosa com caráter de ser não é veículo de ligação entre o protótipo e a coisa supostamente figurada, mas pode, por vezes, ser a própria coisa.

Neste sentido, tomemos como exemplo a imagem no catolicismo, religião com a qual as crenças de matriz africana sofreram um processo de hibridismo, a partir da diáspora negra. Ainda que tenha passado por crises iconoclastas, para o catolicismo "[...] a encarnação do Verbo era o acesso do divino à visibilidade de um corpo, portanto era a abertura ao mundo da imitação clássica, a possibilidade de fazer os corpos participarem nas imagens da arte religiosa" (DIDI-HUBERMAN, 2013, p. 243 apud MACHADO, 2015, p. 82), assumindo a iconografia religiosa o papel de se "fazer ver" a encarnação divina e também encontrando uma função pedagógica, especialmente com a Contrarreforma, ao tornar os ideais cristãos "legíveis" às camadas populares, que não poderiam ler livros, mas tinham acesso às imagens.

No contexto tradicional da religião africana, que por essência não se

6 “descrever o ato de retratar, imaginar a atividade da imaginação, figurar a prática da figuração" (tradução nossa). 
utiliza da escrita como registro, a imagem iconográfica encontra-se profundamente envolvida com a religião ao possuir também caráter funcional de culto, servindo como uma ponte entre o mundo físico e os conceitos invisíveis que permeiam suas crenças, como podemos observar nas palavras de Omatseye e Emeriewen (2010, p. 530),

Most African cultures believe that ancestors and spirits act as intermediaries between the human community, the gods and the Creator. Art objects [...] are used to make the contacts with these spirits. In other words, most African art forms have religion - metaphysical, historical, moral and cultural themes. Such art forms serve as the centre of power, which links man's beliefs, his essence and existence to the physical world.?

Silva (2017, p. 87), que pesquisou sobre a arte religiosa e religião afrobrasileira, menciona os altares e os objetos simbólicos utilizados pelos adeptos da religião quando da "incorporação" como meios principais de presentificação das entidades espirituais destas religiões, posto que "[...] neles as várias divindades existem como força em si e fora de si”. Enquanto referenciais imagéticos bidimensionais, como desenhos, fotografias e pinturas, pode-se citar como referências as pinturas de Carybé e as fotografias de Pierre Verger relativas aos orixás. É interessante notar que enquanto no catolicismo podemos observar a forte presença imagética bidimensional, nas religiões afro-brasileiras a predominância é tridimensional, como os já citados altares, esculturas e objetos simbólicos e de culto.

\section{O PROCESSO DE REALIZAÇÃO DAS IMAGENS}

O primeiro passo para a criação visual neste trabalho foi um diálogo com alguns dos encantados que se apresentam em transe na Casa de Mina de Yemanjá

\footnotetext{
${ }_{7}^{7}$ maioria das culturas africanas acredita que ancestrais e espíritos agem como intermediários entre a comunidade humana, os deuses e o Criador. Objetos de arte [...] são usados para fazer os contatos com esses espíritos. Em outras palavras, a maioria das formas de arte africanas possui religião - temas metafísicos, históricos, morais e culturais. Tais formas de arte servem como o centro de poder, que liga as crenças do homem, sua essência e existência ao mundo físico (tradução nossa).
} 
e Ogum, de Maringá-PR. Em agosto de 2015, com a permissão da Ialorixá Glória de Abê, sacerdotisa da casa, em uma festa aberta ao público, foram abordados alguns caboclos e encantados quanto a este trabalho que se pretendia desenvolver, bem como o objetivo de se criar as "imagens" deles, desenhá-los ou pintá-los (na época ainda não estava definida a técnica que seria utilizada).

Por não ter sido esta a primeira visita ao terreiro, a escolha pelos encantados e caboclos a serem representados não se deu de maneira aleatória, mas foi antes feita de acordo com a percepção pessoal dos pesquisadores, ou seja, por critério de afinidade ou de familiaridade para se aproximar com tal objetivo. Também houve conversas com adeptos da religião sobre a pesquisa, e nestas, não apenas houve uma complementação acerca de alguns conceitos sobre as entidades trabalhadas, como também foram recebidas descrições físicas, simbólicas e imagéticas de outros encantados.

A primeira encantada com a qual dialogamos, Maria Rosa, aceitou de bom grado a proposta de ser representada e foi a que melhor respondeu aos questionamentos sobre como ela se identificaria fisicamente, entre outros aspectos imagéticos. Maria Rosa pertence à família de Codó, que conforme cantiga reproduzida por Prandi e Souza (2011, p. 256, grifo do autor), "São encantados que se orgulbam de serem negros".

Assim, ela começa sua descrição mencionando que ela e todos de sua família são "bem negros", usando como medida "aquele negro que a senhora olha no escuro, e se perde no escuro", e adicionando que todos possuem lábios bem cheios, sendo os dela também "cheio, mas é bem feito". Segundo Maria Rosa, seus olhos seriam levemente puxados, tendo ela, enquanto manifesta em Eliane, filha da Casa e médium que a recebe em transe, puxado levemente seus olhos com as mãos para mostrar o quanto, preocupando-se em deixar clara a medida para que fosse entendido que não eram excessivamente puxados, mas "só mais um cadinho". Ainda segundo ela, seu cabelo é cheio, preto, porém um pouco amarelado porque, segundo ela, "fiquei muito no sol [...], a senhora sabe que o que fica no sol amarela, mas é bem pouco".

Utilizando como medida comparativa Eliane, ela afirmou ter mais altura do que essa e ser mais esbelta, porém não a ponto de ser magra, descrevendo-se como 
"toda roliça". Disse gostar de usar laços, fitas, rendas, e de amarrar seu cabelo, que é cheio, com um laço, atitude reproduzida por Eliane sempre que a "incorporava".

Maria Rosa disse se identificar com as cores de sua guia, ou seja, as cores de sua família mítica, sendo marrom, vermelho, verde, branco riscado de azul e amarelo. Prandi e Souza (2011) afirmam, sobre as cores desta família, que o branco riscado de azul deve-se a uma ligação que eles têm com o vodum Nanã, enquanto a cor marrom remete ao povo Jeje, e o verde e o vermelho representam o povo da mata. Sobre Maria Rosa em específico, os mesmos autores afirmam ser ela "[...] pouco conhecida, tendo se popularizado no Pará", seria madura e "[...] é tida como muito bonita" (PRANDI; SOUZA, 2011, p. 263). A própria Maria Rosa, durante a conversa, afirmou ser conhecida como "a flor do Codó".

Como primeira produção visual, a criação do retrato de Maria Rosa despertou muitas dúvidas iniciais, e apesar do trabalho aqui apresentado ter sido o primeiro finalizado, paralelamente houve outros rascunhos e tentativas. Este trabalho foi, também, o que definiu o parâmetro utilizado para os outros, como a técnica, a disposição, o esquema de cores e o próprio fato de se ter realizado um retrato.

A escolha pelo pastel oleoso sobre papel deu-se pelo fato do pastel oleoso se aproximar muito da pintura na construção da imagem, ao mesmo tempo que seu pigmento denso e pastoso remete à materialidade mais rudimentar. Ao trabalhar com essa técnica é possível modelar e remodelar as formas e as cores de uma forma bastante gestual, pois várias vezes no processo foram utilizadas mãos e unhas, para guiar rastros, traços ou raspar o pigmento para corrigir ou obter efeitos. As cores saturadas e intensas do pastel oleoso também geraram um resultado satisfatório no trabalho.

Ainda assim houve algumas dificuldades, como encontrar a tonalidade correta da pele de acordo com a descrição de Maria Rosa, o que ainda levanta dúvidas se foi conseguido alcançar esse tom. Outra preocupação foi com a representação dos traços negros, sem cometer nenhum "embranquecimento" desses, o que descaracterizaria tanto seu depoimento quanto a própria cultura que se pretende retratar. As cores utilizadas são as cores símbolo de sua família. Maria Rosa, que pôde ver a imagem produzida, e mostrou-se bastante satisfeita com o resultado, pediu uma cópia. Na figura 1, o retrato produzido de Maria Rosa, neste processo. 


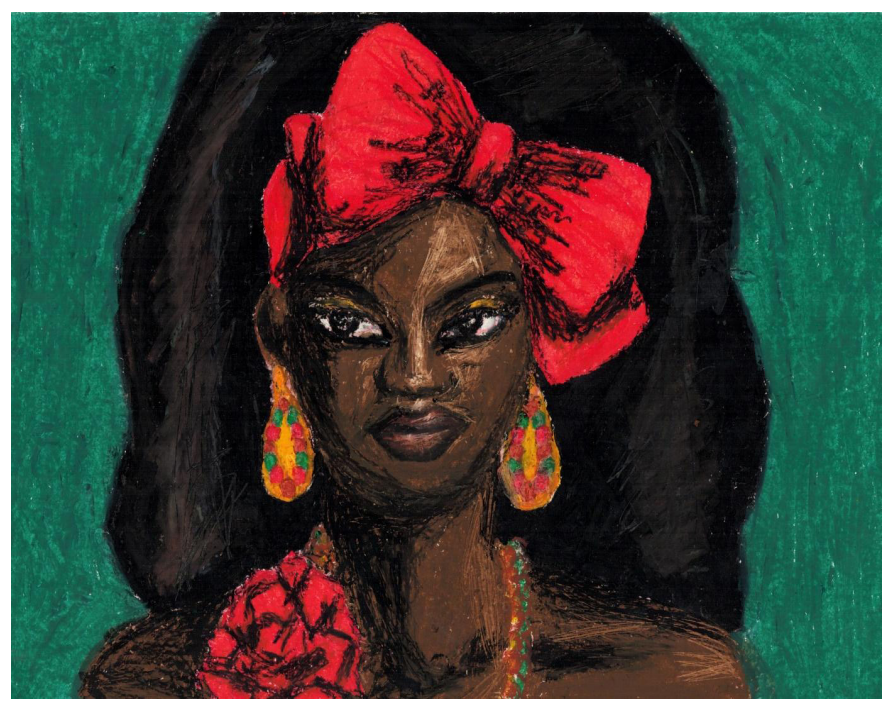

Figura 1. Maria Rosa

Fonte: a autora

Outro encantado com o qual conversamos foi Seu Pedro de Légua, irmão de Maria Rosa e, portanto, pertencente também à família de Codó. Ele manifesta-se por meio de Rodolfho, adepto do Tambor de Mina e filho da Casa. Este encantado foi mais relutante em ceder informações quanto à sua identificação imagética, recorrendo ao bom humor para evitar responder às perguntas enquanto ocorreu o diálogo, afirmando que era para desenhá-lo como uma "assombração", ou recorrendo apenas à instrução para fazê-lo "como quisesse" ou da forma como se imaginava que ele seria - instrução esta recorrente em outras conversas realizadas. Posteriormente, no entanto, o encantado deu duas dicas sobre como retratá-lo: "capricha no chapéu e no bigode".

Seguindo o padrão anterior, as cores utilizadas no retrato de Seu Pedro são de sua família, porém foram dispostas no retrato de maneira diferente de Maria Rosa, assim como a sua orientação, sendo a dela horizontal, e a dele vertical. Esta escolha foi pela disposição do chapéu na composição, que poderia ter mais destaque trabalhando com o papel na vertical. De acordo com as dicas fornecidas por Seu Pedro, o destaque da pintura foi para o chapéu e o bigode, ocultando, de acordo 
com a própria atitude do encantado, mais detalhes sobre sua identidade. Na figura 2, o retrato realizado representando Seu Pedro de Légua.

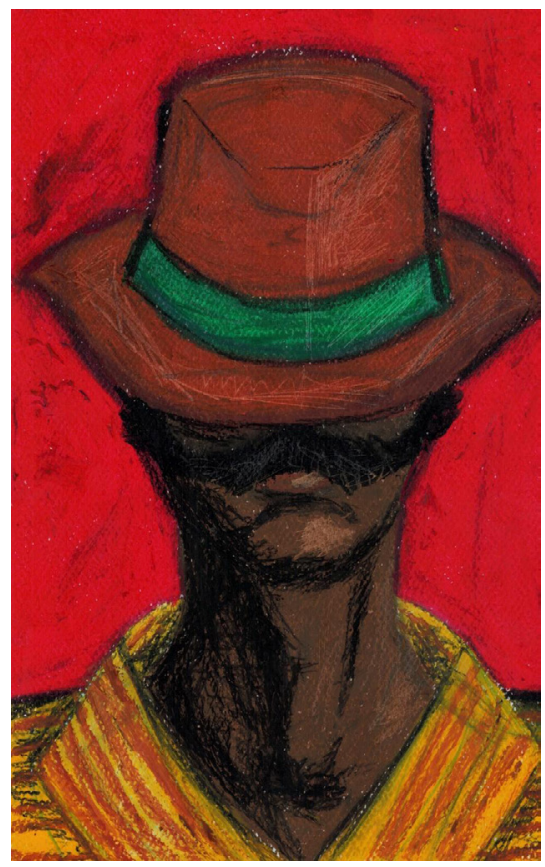

Figura 2. Seu Pedro de Légua

Fonte: a autora

O terceiro encantado aqui apresentado é Laço Ligeiro, pertencente à família dos Boiadeiros (ainda que esta família seja agregada à família codoense). De acordo com Shapanan (2011, p. 324), os Boiadeiros na Mina se assemelhariam "[...] a alguns encantados de mina da família do Codó [...], e misturam-se com os vaqueiros. Estes três grupos - boiadeiros, vaqueiros e codoenses - estariam muito próximos entre si”. O médium que o recebe em transe é Ifadarè Logunedé Tadê (nome de santo), do Asé Oloroke, não sendo adepto do Tambor de Mina, mas um amigo da Casa de Mina onde se deu o estudo. Observa-se, assim, que a encantaria não está exclusivamente relacionada ao Tambor de Mina, efetuando-se o diálogo existente entre as religiões afro-brasileiras.

Pela ausência de oportunidade de conversar diretamente com o encantado Laço Ligeiro quando do levantamento dos dados, Ifadarè Logunedé Tadê foi quem 
forneceu os dados quanto à sua aparência, bem como referenciais visuais, de acordo com seu conhecimento e percepção do encantado. Afirmou que Laço Ligeiro possui entre 35 e 45 anos, é mameluco, de estatura baixa, sem pelos, porém com sobrancelha bem marcada e cabelos até o ombro, presos em uma trança, tem lábios grossos e nariz fino. Não possuía a informação de que o encantado tivesse barba ou bigode. Citou aspectos relativos à sua vestimenta e modos, como o fato do chapéu ser um elemento marcante, e dele gostar de andar descalço, com as barras levantadas até o joelho, algo que também se observa quando o médium o manifesta em transe uma das primeiras coisas que faz é tirar os sapatos e dobrar as barras da calça.

Dentro da percepção deste adepto, Laço Ligeiro está sempre sorridente, por ser muito bem-humorado, e Ifadarè Logunedé Tadê afirmou que se lembra dele sempre ao ver a pintura "O Mulato", de Portinari. Esta imagem foi chave na hora de produzir a pintura, uma vez que foi utilizada como um referencial de produção. $\mathrm{O}$ esquema da imagem segue o mesmo das anteriores, sendo as cores também as da guia, ou da família dos Boiadeiros, no caso, muito semelhante com as da família do Codó: vermelho, verde, marrom e azul riscado de branco.

Posteriormente à produção, surgiu a oportunidade de conversar com o Laço Ligeiro, que elucidou vários aspectos relativos à encantaria e à sua própria história. Ao avaliar a imagem, o mesmo afirmou, com bom humor, ser mais bonito, mas reconheceu as semelhanças com a própria imagem. No entanto, pediu para adicionar a guia no pescoço e a barba, explicando que ela seria rala e localizada apenas no queixo, elementos que não estavam presentes na imagem originalmente. Na figura 3 consta o resultado da produção do retrato de Laço Ligeiro. 


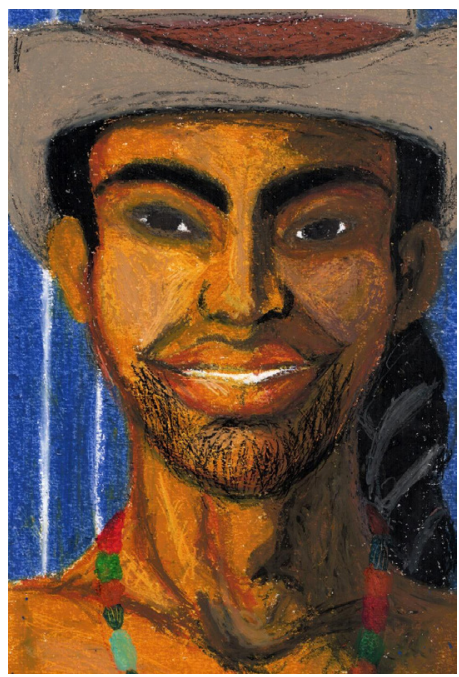

Figura 3. Laço Ligeiro

Fonte: a autora

O retrato de Maria do Balaio foi o próximo a ser produzido. Pertencente à família da Baía, que Prandi e Souza (2011, p. 265-7) definem como "Brincalhões e muito falantes, $[. .$.$] mostram-se sensuais e sedutores, às vezes inconvenientes", e$ especificamente sobre a cabocla, afirmam que ela é "originária da umbanda, mas que facilmente se adaptou ao tambor-de-mina [...]. Tem bom senso de direção, é muito alegre e 'baiadora'”. De fato, Maria do Balaio se apresenta de forma extravagante, divertida e inquieta, mas com um profundo senso de responsabilidade e respeito pela Casa.

A parte mais agitada de seu temperamento dificultou tanto a conversa, pois a única resposta que se obteve dela foi que sua imagem surgiria ao desenhar, quanto uma possível avaliação posterior, pois quando houve oportunidade de mostrar a ela o desenho, esta encontrava-se com a atenção voltada para outros acontecimentos dentro da festa pública, limitando-se a dizer que havia achado bonito.

Prandi e Souza (2011) afirmam que as cores de sua família seriam o verde, amarelo, vermelho e marrom, e por ter a Ialorixá mencionado certa vez que a cor favorita de Maria do Balaio é o vermelho, deu-se predileção ao destaque a essa cor, bem como a cores mais quentes, em seu retrato. $O$ gestual também remete ao já referido temperamento extrovertido, sendo o balaio uma referência ao seu nome, e 
à iconografia que essa cabocla já possui instituída dentro da Umbanda. Na figura 4 apresenta-se o retrato de Maria do Balaio segundo essa percepção.

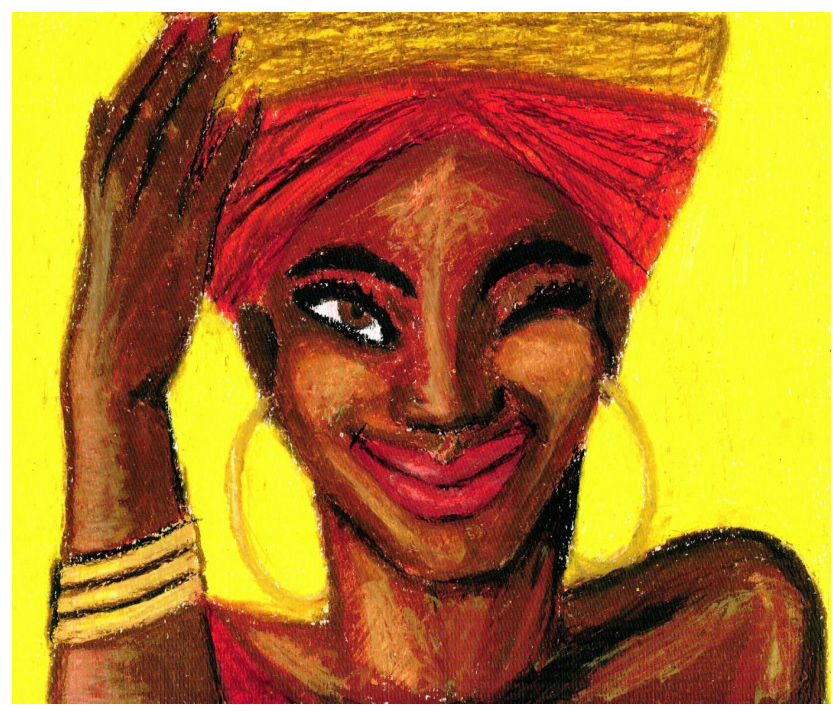

Figura 4. Maria do Balaio

Fonte: a autora

O retrato do Boto Branco, quinto da série, foi o único a ser produzido sem nenhum contato direto com a entidade. Foi novamente Ifadarè Logunedé Tadê, que o recebe em transe, quem forneceu as informações sobre ele. Afirmou ser um encantado originário do Pará, que foi um pescador ou marinheiro e se encantou em um boto. É, também, o único da série a ser descrito com a pele branca. Alto, magro, de cabelo preto engomado e bigode fino, e sobrancelhas grossas. Gosta de se trajar com uma camisa branca aberta, ou apenas um pano, calça, com a barra levantada até perto do joelho, e chapéu branco de abas curtas. Seria um homem muito bonito e mulherengo, porém não muito bem-humorado, que gosta de "baiar" (bailar), fumar e tomar bebidas doces. Pode ser representado como metade homem, metade boto. Ifadarè Logunedé Tadê também afirma haver grande animosidade entre ele e Laço Ligeiro.

Ferretti (2000) afirma que o boto, figura também presente no folclore brasileiro (apesar de ser incerto se, tal qual as lendas amazônicas, os que se manifestam como encantados possam seduzir mulheres), são encantados antigos 
da Mina e que outrora eram numerosos, hoje sendo mais raros e difíceis de se identificar.

Pela relação com os marinheiros, escolheu-se a cor azul como predominante em seu retrato, bem como o branco, cor de predileção em suas vestes e chapéu. Atrás de sua figura, a forma do rabo do boto como elemento de identificação. $\mathrm{O}$ resultado apresenta-se na figura 5.

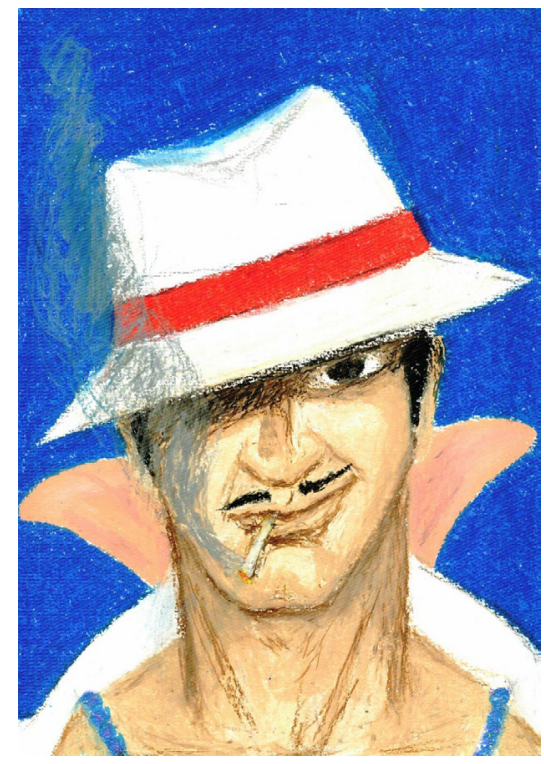

Figura 5. Boto Branco Fonte: a autora

O último retrato produzido foi de Zé do Coco, também pertencente à família da Baía. Ao ser requisitado, ele se negou a se descrever de pronto, mas fez questão de dizer o motivo: "por ordens que não cabe explicar, por regras do povo dessa terra", nem toda entidade tem permissão de se mostrar como é, e mesmo ao próprio médium ele jamais se mostrou, tendo demorado inclusive seis anos para dizer o próprio nome a ele. Segundo ele, este é o seu mistério, apesar de dar plena liberdade para retratá-lo como o imaginar, ele não se mostra. O caboclo conversou sobre vários conceitos interessantes, como sobre o fato do sonho ser o único momento em que quem está encarnado consegue ir para o outro lado e se encontrar com suas entidades. Disse que conheceremos "o outro lado" quando 
desencarnarmos, mas que até lá não podemos saber como é, afinal, não podemos saber como é um lugar onde nunca estivemos, mas apenas imaginar. Afirmou que sabe "como é essa terra porque eu já estive nela", conhecendo os sentimentos como amor, raiva, dor, e que hoje vive outra realidade, mas que nunca se esqueceu da realidade daqui. Afirmou que já viveu muitas experiências encarnado e que certa vez perguntaram a ele como foi a história dele aqui na Terra, ao que ele respondeu "sabe por que eu abomino a traição? Porque foi a traição que me matou", e quando questionado sobre como morreu, respondeu,

isso não importa, eu morri, eu conheci a morte [...] eu senti o que é perder a sua matéria, e não há quem não ame a sua matéria [...] quando chegou o dia que eu tive que me desprender daquela matéria eu sofri, uma dor que a senhora não imagina.

Voltando ao assunto da própria imagem, o baiano reafirmou a liberdade para desenhá-lo como o imaginasse, e disse que seu médium o imaginava de um jeito também, tinha uma figura dele na cabeça, mas que só iria saber como ele realmente era quando desencarnasse. Quando questionado sobre o que achava do presente trabalho, afirmou que

isso é dar formato a uma coisa que não se vê. A senhora não consegue pegar uma fumaça, um vento, a senhora não pega $o$ vento $[\ldots]$ a senhora sente $o$ vento, a senhora sente até o cheiro do vento, mas a senhora nunca vai pegar o vento. $\mathrm{O}$ vento, somos nós, eu sou um vento, Joaquim ${ }^{8}$ é um vento, Pedro é um vento, todos nós somos vento [...]. Povo que tá nessa terra encarnado ainda sente, sente até o cheiro, mas não apanha. Eu estou aqui, e ao mesmo tempo que eu estou aqui falando com a senhora eu estou lá onde a senhora não imagina. Eu estou aqui, nessa Coroa, aqui, nessa terra, e eu posso estar lá na Bahia em cima de uma outra Coroa, vivendo uma outra situação, e sendo o mesmo vento. É o vento que passa aqui chega lá. Então muita coisa acontece... Das águas

${ }^{8}$ Encantado da família dos Boiadeiros que estava presente na festa pública onde se deu o estudo. 
que eu venho, eu sou um caboclo da Umbanda, não sou um caboclo de Tambor-de-Mina, não sou. Eu aqui, na Coroa que eu me encontro [...], estar numa casa de Tambor-de-Mina, eu sinto a tradição de Tambor-de-Mina, mas não sou do Tamborde-Mina [...]. Eu estou aqui. [...]. Nas minhas águas, as águas que eu bebo, diz assim que baiano é o que mais se aproxima do povo da Terra, é o que mais sente o sentimento do povo da Terra. Eu digo assim, esteja à vontade, se a senhora quiser fazer o pintador d'eu da cor que a senhora quiser, do jeito que quiser $[. .$.$] mas eu agradeço a senhora, e desejo que o$ Senhor do Bonfim dê bom sucesso ao trabalho da senhora. Que a senhora tenha a certeza que pra todos nós é de boa valia, grande valia. Porque uma pessoa se interessar em saber quem é o caboclo merece só o respeito.

Ou seja, ainda que não tenha se descrito fisicamente, Zé do Coco falou muito sobre si mesmo, dando conceitos e imagens, e trabalhando outros sentidos, como o olfato (sentir o cheiro do vento).

Ainda que houvesse liberdade para fazê-lo como o imaginasse, tal qual os casos de Pedro de Légua e de Maria do Balaio, seu retrato foi o de elaboração mais difícil, por causa de suas palavras. Foi cogitado seguir vias mais intuitivas e espontâneas, quebrando o aspecto figurativo da série e partindo para a abstração, ou mesmo mudando a técnica do pastel oleoso, cuja matéria e forma de trabalhar passam uma sensação mais pesada, por uma mais fluída, como a aquarela, porém, optou-se por finalizar essa série em específico mantendo um parâmetro comum.

No retrato, foi ocultada sua face por causa do impedimento próprio da entidade em mostrar sua aparência. O gestual, com a mão do lado esquerdo do peito, remete à identificação que o caboclo afirmou ter com os sentimentos humanos dos encarnados. Outros elementos foram baseados no imaginário já constituído da Umbanda em relação a essa entidade. 


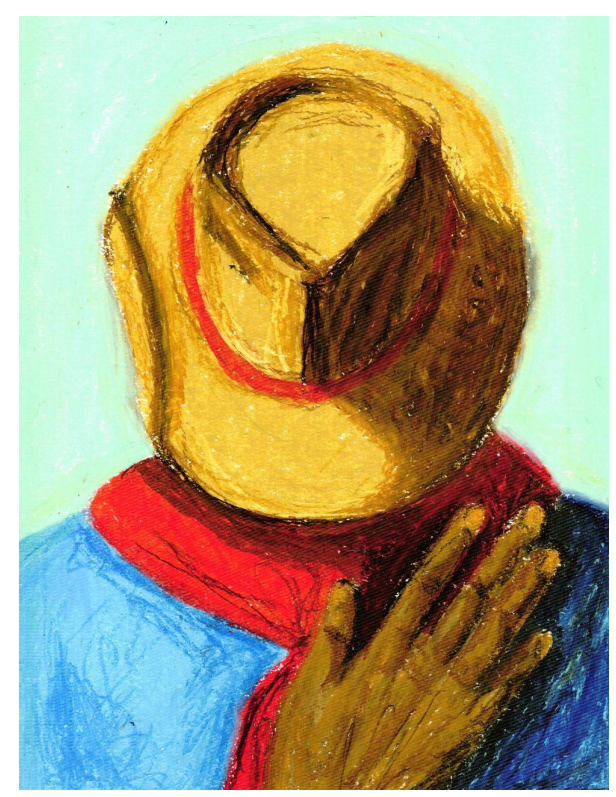

Figura 6. Zé do Coco

Fonte: a autora

Outros praticantes da religião, filhos de santo do terreiro, que têm contato com estes encantados, viram algumas das imagens e alguns reconheceram quem estava nelas retratado. Apenas uma em particular esboçou reprovação, por esta afirmar já tê-los visto em algumas ocasiões e considerá-los muito mais belos do que o retratado, porém adicionando que, tendo a pesquisadora capacidade de vê-los, as pinturas seriam mais fiéis a esta beleza, por serem, já, bem-feitas. A questão da beleza é algo que caminha com o sagrado, o bom ou o virtuoso, e quanto ao que se afirma sobre os encantados a esse respeito, diz que quando se encantam, não só permanecem com a idade que tinham ao se encantarem, como também se tornam mais belos do que quando humanos. 


\section{CONSIDERAÇÕES FINAIS}

Nesta pesquisa, observaram-se questões relacionadas à religião afrobrasileira Tambor de Mina, mediante uma pesquisa bibliográfica e visitações à Casa de Mina de Yemanjá e Ogum, bem como a identidade da encantaria e de alguns de seus encantados perante a religião. Ao buscar suas identificações imagéticas, além das simbólicas já largamente utilizadas no terreiro, em rituais e festas (como guias, panos, objetos e acessórios), foi possível conhecer mais sobre estes seres míticos, importantes tanto para a religião quanto para o folclore e a cultura popular brasileira.

Foi possível também fazer um levantamento bibliográfico breve quanto ao uso da imagem na religião em geral, e em específico nas religiões afro-brasileiras, um assunto vasto e ainda atual e passível de várias pesquisas, por vivenciarmos uma época profundamente marcada pela imagem, assumindo ela um papel fundamental em nossas formações, opiniões, memórias e crenças.

Este trabalho não se encontra fechado $\mathrm{e}$, admitindo as várias possibilidades de prosseguimento, admite-se também que se outras imagens fossem produzidas das mesmas entidades, com as mesmas descrições, estas imagens seriam diferentes a cada novo olhar lançado sobre estes relatos verbais. Portanto, assim como não se pretendeu fechar o trabalho não se pretende, também, estabelecer uma imagem para estes encantados em definitivo, assim como não seria possível criar imagens funcionais como objeto de culto. O que se pretendeu foi uma pesquisa em poéticas visuais que envolveram o fazer de acordo com os relatos das entidades, e uma pesquisa em relação ao uso da imagem como memória material destes perante a religião Tambor de Mina.

\section{REFERÊNCIAS}

ALCANTARA, G. do C. A. de. Terecô: uma tradição negro-brasileira. 2015. Dissertação (Mestrado em Políticas Públicas) - Centro de Educação e Humanidades, Faculdade de Educação, Universidade do Estado do Rio de Janeiro, Rio de Janeiro, 2015. Disponível em: http:/ppfh.com.br/wp-content/uploads/2015/09/Dissert_Giseudado-Carmo-Ananias-de-Alcantara-OK.pdf. Acesso em: 29 maio 2019.

ANDRIOLO, A. O fenômeno da imagem em psicologia social: algumas configurações. 
Psicologia USP, v. 29, n. 1, p. 19-30, 2018. Disponível em: http://www.scielo.br/pdf/ pusp/v29n1/1678-5177-pusp-29-01-19.pdf. Acesso em: 29 maio 2019.

FERRETTI, M. Tambor de Mina e Umbanda: o culto aos caboclos no Maranhão. 1997. Disponível em: http://www.repositorio.ufma.br:8080/jspui/bitstream/1/205/1/ Mina\%20e\%20Umbanda.pdf. Acesso em: 29 maio 2019.

FERRETTI, M. Encantaria maranhense: um encontro do negro, do índio e do branco na cultura afro-brasileira. In: REUNIÃO BRASILEIRA DE ANTROPOLOGIA, 22., 2000, Brasília. Anais [...]. Rio de Janeiro: Associação Brasileira de Antropologia, 2000. p. 15-19.

FONSÊCA, D. de J. de S. Tem mascarado na festa de São Marçal: o brincante de Pai Francisco no Bumba Meu Boi em São Luís-MA. 2015. Dissertação (Mestrado em Arte) - Departamento de Artes Visuais, Instituto de Artes, Universidade de Brasília, Brasília, 2015. Disponível em: http://repositorio.unb.br/bitstream/10482/18909/1/2015 DanielledeJesusdeSouzaFonseca.pdf. Acesso em: 28 maio 2019.

ICONOGRAFIA. In: MICHAELIS. Dicionário de Português Online. São Paulo: Melhoramentos, 2019. Disponível em: https://michaelis.uol.com.br/modernoportugues/busca/portugues-brasileiro/iconografia/. Acesso em: 28 maio 2019.

LIMA, L. L. da C.; SAMPAIO, S. M. G. Algumas reflexões sobre o Tambor de Mina e os terreiros de Porto Velho. Revista Veredas Amazônicas, v. 3, n. 1, jan./jun. 2014. Disponível em: http://www.periodicos.unir.br/index.php/veredasamazonicas/article/ view/1237/1305. Acesso em: 29 maio 2019.

LOPES, M. A. O. Introdução à arte afro-brasileira. In: SIMPÓSIO NACIONAL DE HISTÓRIA, 28., 2015, Florianópolis. Anais [...]. São Paulo: Associação Nacional de História, 2015. p. 27-31. Disponível em: http://www.snh2011.anpuh.org/resources/ anais/39/1444327678_ARQUIVO_introduc_a_oaarteafrobrasileira3.pdf. Acesso em: 28 maio 2019.

MACHADO, R. de $S$. Análise de imagem figurativa: entre limites e possibilidades no campo da História da Arte. Revista Humus, v. 5, n. 13, 2015. Disponível em: $\quad$ http://www.periodicoseletronicos.ufma.br/index.php/revistahumus/article/ download/3194/2969. Acesso em: 29 maio 2019. 
MITCHELL, W. J. T. Iconology: image, text, ideology. Chicago: The University of Chicago Press, 1986.

OMATSEYE, B. O. J.; EMERIEWEN, K. O. An appraisal of religious art and symbolic beliefs in the traditional African context. African Research Review, v. 4, n. 2, p. 529-544, apr. 2010. Disponível em: http://www.ajol.info/index.php/afrrev/article/ viewFile/58370/46717. Acesso em: 16 nov. 2015.

PELEGRINELLI, A. L. M. Imagem como documento para a história das religiões: conceitos e aplicação. In: SEMINÁRIO DE PESQUISAS DO LABORATÓRIO DE ESTUDOS SOBRE AS RELIGIÕES E RELIGIOSIDADES, 2., 2014, Londrina. Anais [...]. Londrina: Universidade Estadual de Londrina, 2014. Disponível em: http://www.uel. br/laboratorios/religiosidade/pages/arquivos/Anais\%20II\%20Encontro\%20do\%20 LERR.pdf. Acesso em: 19 nov. 2015.

PRANDI, R. Nas pegadas dos Voduns: um terreiro de Tambor-de-Mina em São Paulo. In: MOURA, C. E. M. de (org.). Somavó, o amanhã nunca termina. São Paulo: Empório de Produção, 2005. p. 63-94.

PRANDI, R.; SOUZA, P. R. de. Encantaria de Mina em São Paulo. In: PRANDI, R. (org.). Encantaria brasileira: o livro dos mestres, caboclos e encantados. Rio de Janeiro: Pallas, 2011.

RUSSO, D. O conceito de imagem-presença na Arte da Idade-Média. Revista de História, São Paulo, n. 165, p. 37-72, jul./dez. 2011.

SHAPANAN, F. de. Entre caboclos e encantados: mudanças recentes em cultos de caboclo na perspectiva de um chefe de terreiro. In: PRANDI, R. (org.) Encantaria Brasileira: o livro dos mestres, caboclos e encantados. Rio de Janeiro: Pallas, 2011.

SILVA, V. G. da. Religião e identidade cultural negra: afro-brasileiros, católicos e evangélicos. Afro-Ásia, v. 56, p. 83-128, 2017. Disponível em: https://portalseer. ufba.br/index.php/afroasia/article/view/22524/15682. Acesso em: 30 maio 2019. 